\title{
A comparison of effects measured with isotonic and isometric recording: I. Concentration-effect curves for agonists
}

\author{
${ }^{*, 1}$ R.B. Barlow, ${ }^{1}$ Susan M. Bond, ${ }^{1}$ Claire Grant, ${ }^{1}$ D.S. McQueen \& ${ }^{1}$ Zeenat Yaqoob
}

${ }^{1}$ Department of Neuroscience, 1 George Square, Edinburgh EH8 9JZ, Scotland

1 Concentration-effect curves were obtained with carbachol tested on isolated preparations of guinea-pig ileum taken from adjacent sites in the same animal, one recorded isotonically, the other isometrically: similar experiments were made with histamine as agonist and with carbachol on rat uterus (in oestrus).

2 The position and steepness of the curves was expressed as the values of $\left[\mathrm{EC}_{50}\right]$ and the exponent, P: with carbachol or histamine on guinea-pig ileum the curves were significantly steeper with isotonic recording $(P<0.02$, sign test $)$ and displaced towards lower concentrations $(P<0.005)$ but there were significant correlations $(P<0.05)$ between values obtained with tissues from the same animal.

3 The curves for carbachol on the rat uterus were very steep: with isotonic recording the exponent (often eight or more) was consistently higher than with isometric $(P<0.001)$ : there was no significant displacement but there was a significant correlation $(P<0.05)$ between values of $\left[\mathrm{EC}_{50}\right]$ obtained with tissues from the same animal.

4 Although the results obtained by the two methods are different, they are correlated.

5 These effects are to be expected because with isotonic recording there can be no change in length until the tension exceeds the load and the tissue bulk sets an upper limit to shortening: the range within which an effect can be measured (the 'operational window') is smaller. The observed effects on $\left[\mathrm{EC}_{50}\right]$ and $\mathrm{P}$ have been reproduced with theoretical data.

British Journal of Pharmacology (2001) 133, 1081-1086

Keywords: Concentration-effect curves; guinea-pig ileum; rat uterus in oestrus; carbachol; histamine; isotonic recording; isometric recording; operational windows

Abbreviations: $\mathrm{BL}$, baseline for effects; $\mathrm{BL} \%$, baseline expressed as $\%$ maximum response; $\mathrm{EC}_{50} \mathrm{ratio} \mathrm{M} / \mathrm{T}$, ratio of isometric to isotonic values of $\mathrm{EC}_{50}$ : $\mathrm{P}$, exponent in an empirical model for a concentration-effect curve (equation 1); $\mathrm{P}^{\prime}$, the exponent obtained by fitting points from a theoretical signal curve lying within a particular window

\section{Introduction}

The relation between the effect (response) produced by a drug and its concentration, plotted logarithmically, is sigmoid and empirically can be fitted to the equation:

$$
\mathrm{E}=\frac{\mathrm{M}-[\mathrm{A}]^{\mathrm{P}}-}{[\mathrm{A}]^{\mathrm{P}}+\left[\mathrm{EC}_{50}\right]^{\mathrm{P}}}
$$

where the concentration, $[\mathrm{A}]$, produces the effect, $\mathrm{E},\left[\mathrm{EC}_{50}\right]$ produces a half-maximal response $(\mathrm{M} / 2)$ and the exponent, $\mathrm{P}$ (also referred to as the Hill coefficient, $\mathrm{n}_{\mathrm{H}}$ ), determines the steepness of the curve (Parker \& Waud, 1971). It has long been known that the positions of agonist curves, given by values of $\left[\mathrm{EC}_{50}\right]$, vary greatly and preparations where this is high are regarded as 'insensitive'. With the advent of the computer-fitting of data it has been possible to make quantitative comparisons between the steepness of the curves using P. For the one-to-one binding of drug to receptor, $\mathrm{P}=1$, but in a recent survey of published curves (Barlow, $1999)$ values ranged from very flat $(\mathrm{P}=0.2)$ to very steep $(\mathrm{P}=8)$. It is not possible to explain these differences mechanistically because the steps between the binding of an agonist to a receptor and the response are not known but

*Author for correspondence at: Ash Lea Cottage, Ravenstonedale, Kirkby Stephen, Cumbria CA17 4NG. the exponent is of practical value because a preparation with a steep curve is needed for a sensitive biological test.

This paper describes an investigation of the effects of the method of recording mechanical responses from smooth muscle on the shapes of agonist concentration-effect curves by making experiments with adjacent pieces of tissue from the same animal and recording isotonically with one and isometrically with the other using the same load. Two types of tissue were studied, guinea-pig ileum and rat uterus in oestrus (which has a very steep concentration-effect curve, Edinburgh Staff, 1970). These were a first step in a study of the effects of the method of recording on antagonist curves (described in Part II).

\section{Methods}

Concentration-effect curves were obtained with isolated preparations of ileum from Dunkin-Hartley guinea-pigs $(200-250 \mathrm{~g})$. These were killed by stunning and exsanguination, in accordance with Home Office regulations, and preparations were set up as described by Edinburgh Staff (1970) in Krebs' solution containing $0.1 \mathrm{~mm}$ hexamethonium and aerated with oxygen $+5 \% \mathrm{CO}_{2}$ at $37^{\circ} \mathrm{C}$. Two adjacent pieces of tissue were used in each experiment: with one the 
contractions were recorded isotonically with a load of $0.5 \mathrm{~g}$ and with the other the tension was recorded isometrically with an initial tension of $0.5 \mathrm{~g}$. The agonist was added manually: in one set of experiments it was carbachol, in another it was histamine. The contact time was $30 \mathrm{~s}$ with doses applied every $3 \mathrm{~min}$.

Similar experiments were made with the isolated rat uterus preparation from female Wistar rats $(280-330 \mathrm{~g})$ on day 1 of the cycle, as indicated by the presence of cornified epithelial cells in vaginal smears taken daily. Animals were killed by stunning and exsanguination and preparations were set up as described by Edinburgh Staff (1970) in de Jalon's solution at $31^{\circ} \mathrm{C}$. In each experiment two strips from the same animal were tested, one with isotonic recording, the other with isometric and each with a load of $0.5 \mathrm{~g}$. The agonist was carbachol, added manually with a contact time of $45 \mathrm{~s}$ and doses applied every $3 \mathrm{~min}$.

\section{Data analysis}

The program SPICE (Bailey et al., 1998) was used to fit values of response and agonist concentration by least-squares to equation 1 or a similar equation allowing for a baseline (BL):

$$
\mathrm{E}=\underset{[\mathrm{A}]^{\mathrm{P}}+\left[\mathrm{EC}_{50}\right]^{\mathrm{P}}}{\mathrm{M}}+\mathrm{BL}
$$

This gives estimates of $[\mathrm{EC}]_{50}$, the exponent, $\mathrm{P}$, and $\mathrm{BL}$ (baseline where appropriate). Carbachol chloride, hexamethonium bromide, histamine, $(-)$ adrenaline and $(-)$ and $( \pm)$ isoprenaline were obtained from Sigma.

All responses were recorded with a Maclab system.

\section{Statistical tests}

A sign test was used to investigate differences between isotonic and isometric recording with tissues from the same animal: paired $t$-tests and signed rank tests were also used. Pooled data were compared using $t$-tests and U-tests. Correlations were tested with parametric (r, Student's $t$ ) and nonparametric (Spearman's rank coefficient) methods.

\section{Results}

Sample log.concentration-effect curves using isotonic and isometric recording with adjacent pieces of tissue from the same animal are shown in Figure 1. All values of $\left[\mathrm{EC}_{50}\right]$ and $\mathrm{P}$ (for carbachol and histamine with ileum and for carbachol with uterus) are summarized in Table 1. In 19 out of 20 experiments with ileum $\left[\mathrm{EC}_{50}\right]$ for the agonist was higher with isometric recording $(P<0.005$, sign test $)$ and the ratio of the values $(\mathrm{M} / \mathrm{T}$ in Table 1$)$ was greater than 1. In 16 out of 20 the curves were flatter $(P<0.02)$. Even when the data are pooled there are differences between the mean values of $\left[\mathrm{EC}_{50}\right]$ and of $\mathrm{P}$, which are significant (Table 1). A 2-factor analysis of variance (which retains the pairing of results) was made for effects of method and animal and the $\left[\mathrm{EC}_{50}\right]$ values for carbachol and histamine showed a significant effect of method (F-values of 7.4 and 22.6 respectively: $P<0.05)$. Although different, there are significant correlations between the values: Figure 2 (upper
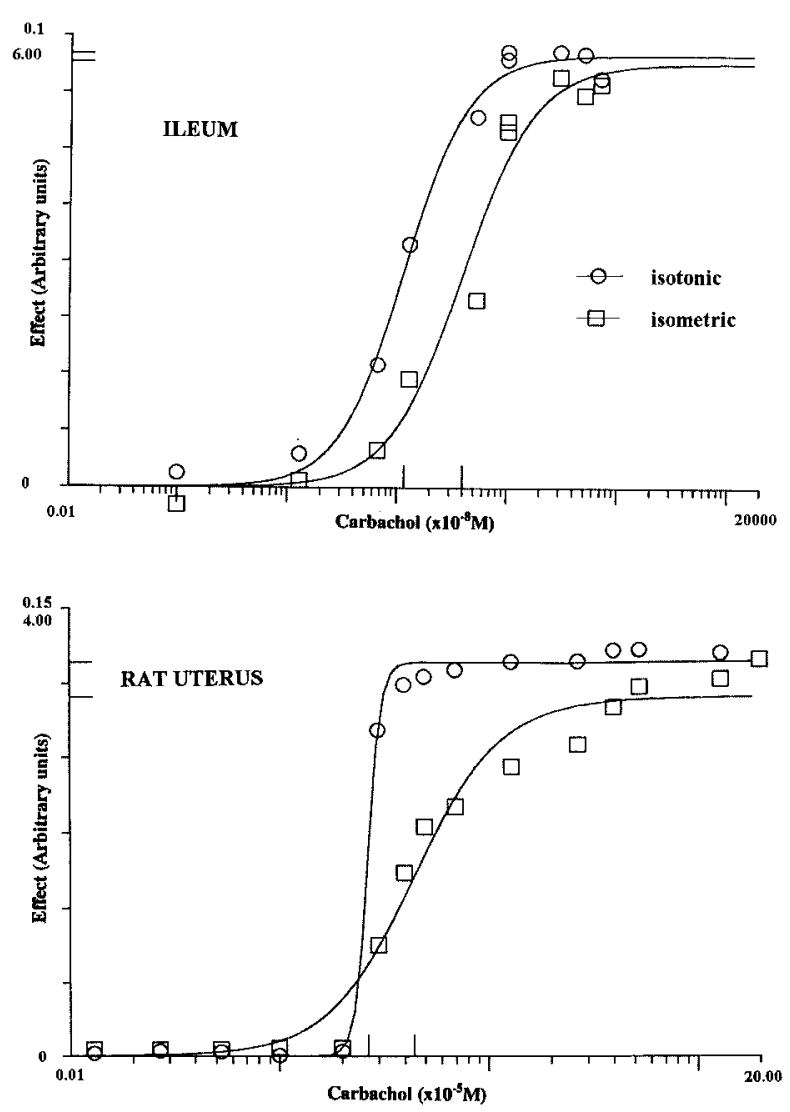

Figure 1 Concentration-effect curves for carbachol with samples of adjacent tissue from guinea-pig ileum and from rat uterus in oestrus recorded isotonically and isometrically. The scales have been chosen so that the graphs are of roughly comparable height with the maxima indicated on the ordinate: values of $\left[\mathrm{EC}_{50}\right]$ are marked on the abscissa.

left) shows isometric values of $\left[\mathrm{EC}_{50}\right]$ for carbachol and histamine on guinea-pig ileum plotted against isotonic values. With all 20 points the Spearman rank correlation coefficient is $0.51 \quad(P<0.05)$. There is also a significant correlation $(P<0.05)$ between values of $\mathrm{P}$ (Figure 2 upper right).

In all experiments with rat uterus $\mathrm{P}$ was bigger for isotonic recording than for isometric $(P<0.001)$ but there was no significant correlation (Figure 2, lower right). There was only a small increase in $\left[\mathrm{EC}_{50}\right]$, which was not significant (paired $t$ test, signed rank test) but there is a significant correlation $(P<0.05)$ between the values obtained by the two methods (Figure 2, lower left).

\section{Discussion}

Tissue preparations differ in the concentrations of agonist which produce an effect and the range of values of $\left[\mathrm{EC}_{50}\right]$ obtained in this work can be seen in Table 1. There are clear differences between the values of $\left[\mathrm{EC}_{50}\right]$ and $\mathrm{P}$ using different methods of recording and tissue from the same animal. Because of the experimental plan, differences between results obtained with the two methods could be detected in spite of 
Table 1 Individual agonist concentration-effect curves in experiments with tissue from the same animal fitted to equation 2 with baseline as a percentage of the maximum

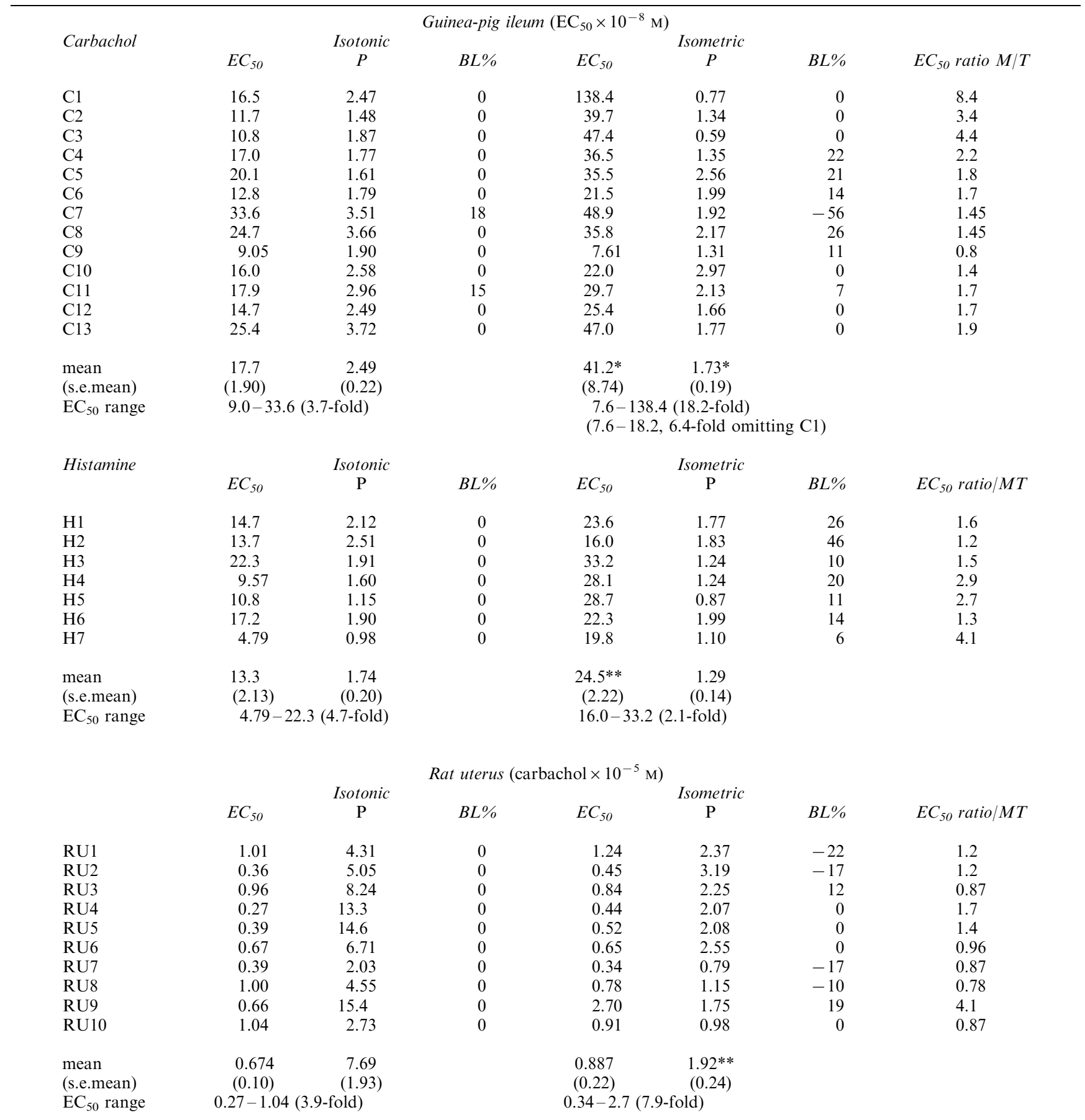

the wide range in the sensitivity of tissues from different animals (shown by the values of $\left[\mathrm{EC}_{50}\right]$ and $\mathrm{P}$ ). Although detectably different, these values should be correlated (as has been found) if both are dependent on a factor which may vary between animals (such as the relation between signal and muscle response). Because results were obtained with two agonists operating on different receptors it is possible to see that the effect of the method does not appear to depend which agonist was used.

The results are to be expected because with isotonic recording there can be no change in length until the tension exceeds the load and, at the upper end of the curve, the tissue bulk sets a limit to shortening. In the experiments with ileum, for instance, higher concentrations of agonist could increase 

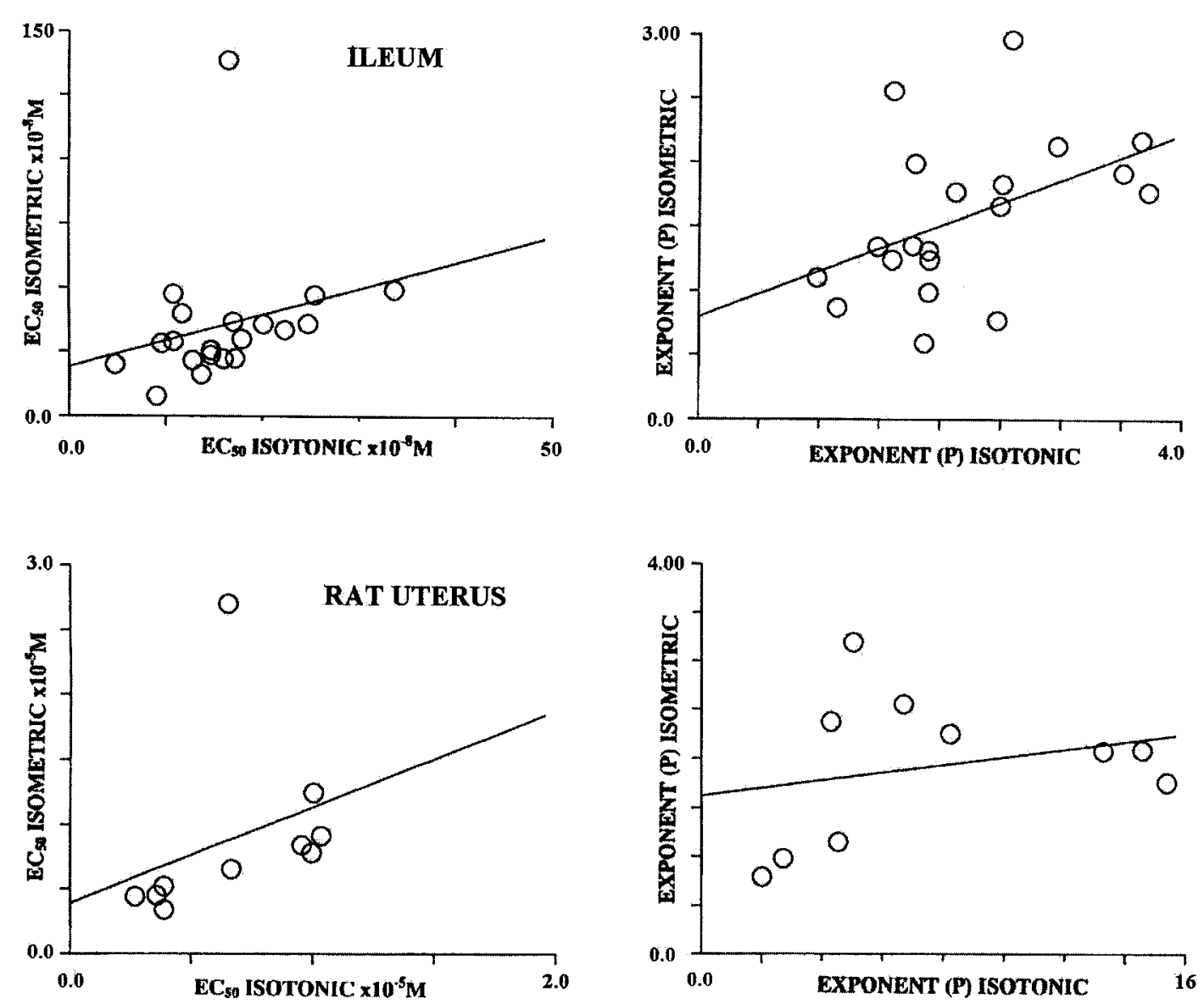

Figure 2 Upper: values of $\left[\mathrm{EC}_{50}\right]$ and of $\mathrm{P}$ for guinea-pig ileum with isometric recording plotted against values with isotonic recording; pooled results for carbachol and histamine. Lower: values of $\left[\mathrm{EC}_{50}\right]$ and of $\mathrm{P}$ for carbachol and rat uterus in oestrus plotted similarly.

tension even though the tissue could not contract further. There is a narrower range ('operational window') within which an effect can be measured with isotonic recording.

The effect of such limits should depend on their position and the steepness of the 'signal' curve (for the process leading to the response) and has been studied with theoretical data obtained from 25 evenly spaced points on a curve given by:

$$
\mathrm{E}=\frac{\mathrm{M}_{-}[\mathrm{A}]^{\mathrm{P}}-}{[\mathrm{A}]^{\mathrm{P}}+\left[\mathrm{A}_{50}\right]^{\mathrm{P}}}
$$

with $\mathrm{M}=1,\left[\mathrm{~A}_{50}\right]=1$ and $\mathrm{P}=0.5,1.0$ or 1.5 . The points lying within particular limits were then fitted to equation 1 with the value of $M$ determined by the width of the window. The effect of a lower limit (threshold) is shown in Figure 3A: this selects the upper part of the signal curve and increases $\left[\mathrm{EC}_{50}\right]$. The effect of an upper limit is shown in Figure 3B: this selects the lower part of the signal curve and decreases $\left[\mathrm{EC}_{50}\right]$. The effects on $\left[\mathrm{EC}_{50}\right]$ of the steepness of the signal curve and the positions of the limits are shown in Figure $3 \mathrm{C}$ and $\mathrm{D}$ and are much greater when the signal curve is flat $(\mathrm{P}=0.5$ in equation 3 ). The effects on the exponent $\mathrm{P}^{\prime}$, indicating steepness of the theoretical concentration-effect curve, are shown in Figure 3E and F. Any window steepens this curve, because it decreases the range within which the response goes from zero to maximum. There are irregularities in values of the exponent $\mathrm{P}^{\prime}$ when the operational window is very narrow and so encloses only a few points, e.g. when the threshold is high (Figure 3E) or the upper limit is low (Figure 3F).

These effects are not dependent upon the actual equation used to represent the signal curve: they apply to any relationship giving a curve of similar shape. With isotonic recording the effect of the threshold, which should increase $\left[\mathrm{EC}_{50}\right]$, appears to be more than offset by the low upper limit (associated with bulk), hence the lower value than with isometric recording. The narrower operational window steepens the curve. The extremely steep curve obtained with isotonic recording and the rat uterus in oestrus suggests that the response is almost all-or-none, as might be expected if, once above a threshold, the signal triggers a coordinated response limited by bulk. With such steep curves it seems unlikely that there will be detectable differences in [EC $\left.{ }_{50}\right]$.

With the tissues used in this work the agonists probably produce their effects on tension or shortening by increasing the internal concentration of calcium ions, and it seems possible that this may also operate within a window. The relation between tension and internal calcium has a remarkably steep response curve (Shiraishi et al., 1998), comparable with that for carbachol and the rat uterus in 

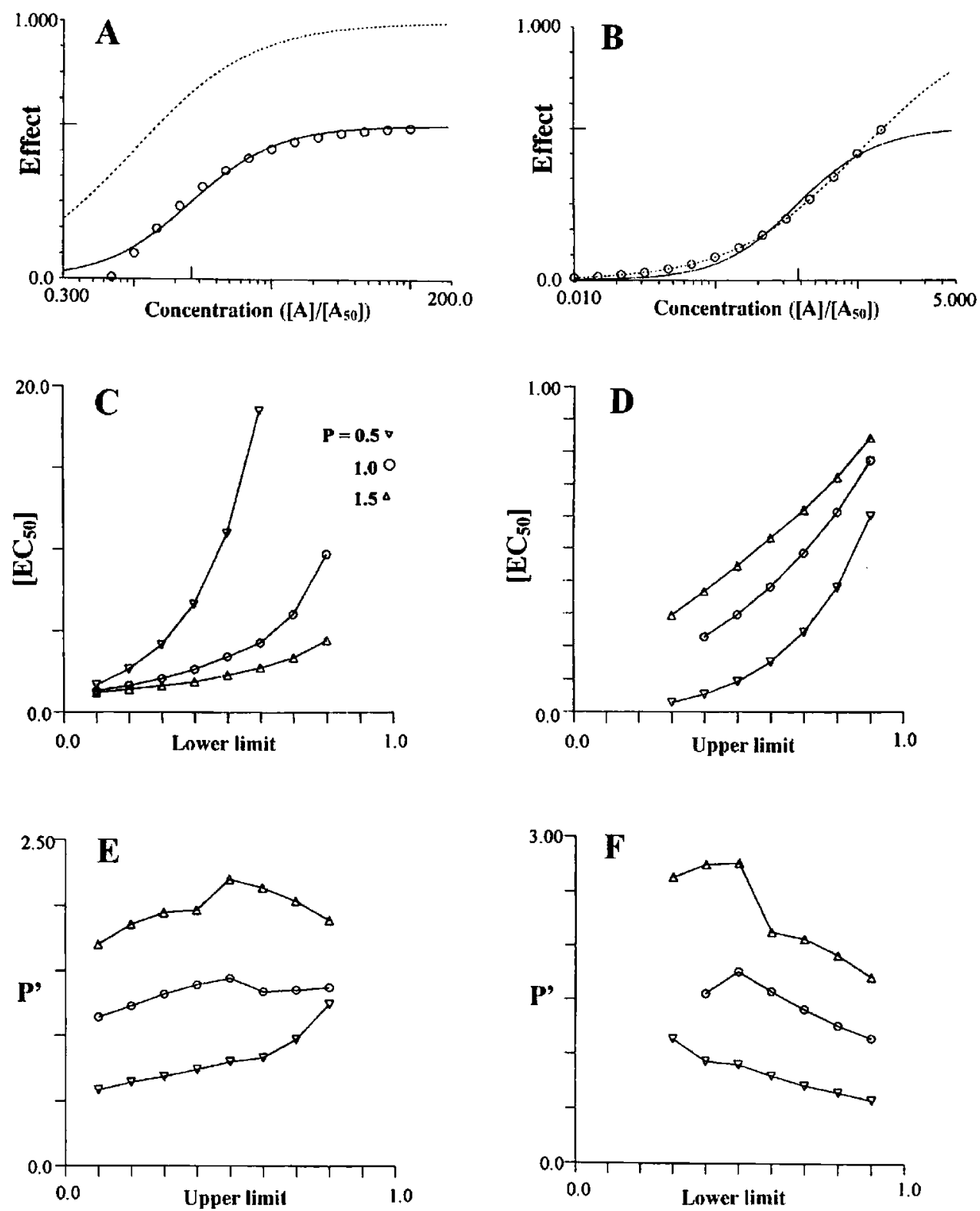

Figure 3 (A and B) Effects of operational windows on log.concentration ([A])- effect (E) curves. The signal curve (broken line) has $\mathrm{M}=1,\left[\mathrm{~A}_{50}\right]$ and $\mathrm{P}=1$ : in $(\mathrm{A})$ the threshold is 0.4 and the upper limit is 1.0 : the fitted curve has $\mathrm{P}^{\prime}=1.39$ and $\left[\mathrm{EC}_{50}\right]=2.63$, marked on the abscissa. In (3B) the threshold is zero and the upper limit is $0.6: \mathrm{P}^{\prime}=1.58$ and $\left[\mathrm{EC}_{50}\right]=0.38$. The line shows the least-squares fit to

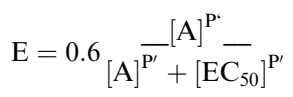

(C and D) show the effects of the steepness of the signal curve ( $\mathrm{P}$ in equation 3 ) and the window (threshold in $\mathrm{C}$, upper limit in $\mathrm{D}$ ) on $\left[\mathrm{EC}_{50}\right]$. $(\mathrm{E}$ and $\mathrm{F})$ show in the same way the effects on the steepness, $\mathrm{P}^{\prime}$, of the concentration-effect curve.

oestrus in de Jalon's solution (which has a low concentration of calcium ions). There is effectively a threshold below which there is no change in tension, so whatever the mechanism that generates the signal there appears to be a lower window. Lew \& Flanders (1999) call this 'threshold inertia'. Such a threshold should be particularly important for compounds, which act as physiological antagonists by producing the opposite effect, because it will limit their action. Experiments with these are described in part II.

We thank Dr David Wyllie for his valued criticism of this manuscript and Dr N.L. Poyser for the vaginal smear tests in rats. 


\section{References}

BAILEY, S.R., BARLOW, R.B., ELLIOTT, J. \& GRAY, G.A. (1998). SPICE - a simple program identifying curvaceous elements. Br. $J$. Pharmacol., 124, 142P.

BARLOW, R.B. (1999). A survey of the slopes of concentrationresponse curves. Br. J. Pharmacol., 128, 301P.

EDINBURGH STAFF. (1970). Pharmacological Experiments on Isolated Preparations, 2nd edn. pp 2, 58-60, 94-95. Edinburgh: Churchill-Livingstone.

PARKER, R.B. \& WAUD, D.R. (1971). Pharmacological estimation of drug-receptor dissociation constants. Statistical evaluation. I Agonists. J. Pharmacol. Exp. Ther., 177, 1-12.
LEW, M.J. \& FLANDERS, S. (1999). Mechanisms of melatonininduced vasoconstriction in the rat tail artery; a paradigm of weak vasoconstriction. Br. J. Pharmacol., 126, $1408-1418$.

SHIRAISHI, Y., KANMURA, Y. \& ITOH, T. (1998). Effect of cilostazol, a phosphodiesterase type III inhibitor, on histamine-induced increase in $\left[\mathrm{Ca}^{2+}\right]_{\mathrm{i}}$ and force in middle cerebral artery of the rabbit. Br. J. Pharmacol., 123, 869-878.

(Received April 10, 2001 Revised May 14, 2001 Accepted May 15, 2001) 